\title{
RESPONSABILIDADE SOCIAL E A ÉTICA NO USO DE MÉTODOS QUANTITATIVOS NO ENSINO SUPERIOR
}

SOCIAL RESPONSIBILITY AND ETHICS IN THE USAGE OF QUANTITATIVE METHODS IN HIGHER EDUCATION

Wladimir Colman de Azevedo Junior', Alexandre Magno de Melo Faria² e Marcos Rodrigues ${ }^{3}$

RECEBIDO EM:19/07/2016 | APROVADO EM:22/05/2017

DOI: $10.5902 / 2317175823157$

\begin{abstract}
RESUMO
O presente estudo busca identificar as consequências da má conduta na utilização de métodos quantitativos empregados na investigação científica sobre a Responsabilidade Social das Instituições de Ensino Superior do Brasil. Utilizando pesquisa bibliográfica, identificou-se que a ausência de ética na gestão dos métodos quantitativos pode levar a inferências fraudulentas. A consequência seria o atraso na evolução do conhecimento científico e do desenvolvimento da sociedade. Dessa forma, a responsabilidade social poderá ser alcançada se as instituições citadas incentivarem e monitorarem as motivações de seus pesquisadores e o tratamento dos dados recolhidos através da inibição da pesquisa não-científica.
\end{abstract}

Palavras-chave: Ética; Métodos Quantitativos; Instituições de Ensino Superior.

\footnotetext{
1 Economista formado na Universidade Federal de Mato Grosso (UFMT), mestre em Agronegócio e Desenvolvimento Regional, pela mesma instituição, atualmente curso doutorado em Desenvolvimento Sustentável do Trópico Úmido no Núcleo de Altos Estudos Amazônicos (NAEA), da Universidade Federal do Pará (UFPA). E-mail: azevedocolman@gmail.com.

2 Economista (UFMT), mestre e doutor em Desenvolvimento Socioambiental pelo Núcleo de Altos Estudos Amazônicos (NAEA) da Universidade Federal do Pará (UFPA). Pós-doutor em Gestão e Economia pela Universidade da Beira Interior (UBI/Portugal), com bolsa do Programa Ciência sem Fronteiras da CAPES. Professor Adjunto IV da Faculdade de Economia da UFMT, Campus Cuiabá. Atua na área de economia, com ênfase em desenvolvimento socioambiental, economia ecológica e dinâmica agrária. E-mail: dr.melofaria@ gmail.com.

3 Doutorando em Desenvolvimento Sustentável pela Universidade Federal do Pará (UFPA). Mestre em Agronegócios e Desenvolvimento Regional pela Universidade Federal do Estado de Mato Grosso (UFMT). Atualmente é professor Assistente A na Universidade Federal da Amazônia (UFRA). Tem experiência na área de Economia, com foco de pesquisa em: Agricultura Familiar, Agronegócios, Cadeias Produtivas e Mercados de Comercialização da produção agroindustrial. E-mail: marcos.rodrigues.adm@gmail.com.
} 
RESPONSABILIDADE SOCIAL E A ÉTICA NO USO DE MÉTODOS QUANTITATIVOS NO ENSINO SUPERIOR

\begin{abstract}
The purpose of this study is to identify the consequences of misconduct during the usage of quantitative methods used in scientific research about the Social Responsibility of Brazil's Higher Education Institutions. Using bibliographic research, it was identified that the absence of ethics, in the management of quantitative methods, can lead to fraudulent inferences. The consequence would be the delay in the evolution of scientific knowledge and the society's development. For this reason, the social responsibility can be achieved if the Educational Institutions encourage and monitor the motivations of their researchers and the treatment of the collected data, by the inhibition of unscientific research.
\end{abstract}

Keywords: Ethics; Quantitative Methods; Higher Education Institutions.

\title{
1 Introdução
}

As Instituições de Ensino Superior (IES), sobretudo as públicas, têm se consolidado como espaço institucional de desenvolvimento científico no Brasil (Chiarini e Vieria, 2012). A formação e atualização de cientistas, bem como a oferta de condições e recursos para efetivação de projetos de pesquisa, se concentram nesses espaços educacionais. A responsabilidade das IES demandada pela sociedade é representada pelos instrumentos legais que estabelecem os meios de avaliação da educação superior brasileira. A Lei Federal No 10.861 de 14 de abril de 2004 e a Portaria No 2.501 de 9 de julho de 2004 firmam regras de avaliação das Instituições de Ensino Superior a partir de 10 dimensões, dentre as quais encontra-se a "Responsabilidade Social". Esta seria a dimensão avaliativa do trabalho científico e educacional das universidades e institutos frente às demandas sociais (BRASIL, 2004a; BRASIL, 2004b).

A Responsabilidade Social refere-se à inserção das atividades individuais dos agentes públicos e privados no ambiente social, orientando-se pela garantia à dignidade, à liberdade e à autonomia do ser humano, conforme os preceitos éticos aristotélicos (Calovi e Marmentini, 2010; Lima et al., 2012; Sangali e Stefani (2012). Reconhecendo, como afirmam Chiarini e Vieira (2012), que as IES são consideradas como lócus de desenvolvimento da pesquisa científica e tecnológica no Brasil, e que esse desenvolvimento deve respeitar as normas éticas socialmente estabelecidas e manifestadas por meio da dimensão Responsabilidade Social, torna-se notória a necessidade de estabelecimento de normas éticas formais a serem seguidas durante a elaboração e execução de projetos e durante o processo de ensino.

Essa formalização vem sendo direcionada ao estabelecimento de legislação normativa referente aos procedimentos realizados em seres humanos e animais que se baseiam no Código de Nuremberg, de 1947, e na Declara- 
ção Universal dos Direitos Humanos, de 1948, ambos construídos com vistas a inibir pesquisas como as realizadas durante a Segunda Guerra Mundial, bem como a Declaração Universal sobre Bioética e Direitos Humanos de 2005 (FERREIRA; SAMPAIO, 2013; MIRANDA, 2006).

Esses documentos têm como foco a definição de normatizações éticas direcionadas para pesquisas realizadas em humanos e animais, cujos objetivos dependem de manipulação genética, administração de medicamentos e outros procedimentos invasivos realizados diretamente na concretude do ser vivo, como observado em trabalhos relacionados às Ciências da Saúde e Biológicas. Atividades científicas que tenham como objeto de estudo o conhecimento tradicional associado também vêm sendo normatizadas devido à necessidade de caracterização da propriedade de tal conhecimento (FERREIRA; SAMPAIO, 2013).

A normatização mencionada proporcionou o estabelecimento de uma estrutura administrativa responsável pela supervisão do cumprimento das regras necessárias à garantia do comportamento ético nas pesquisas com as características citadas. Como, por exemplo, o sistema CEP/CONEP, composto pela Comissão Nacional de Ética em Pesquisa (CONEP) e os Comitês de Ética em Pesquisa (CEP) presentes nas instituições de pesquisa. Considerando a regularidade, essa estrutura permite a avaliação dos procedimentos metodológicos adotados. Esses trabalhos terão os métodos quantitativos, que são analisados e validados éticamente (FERREIRA; SAMPAIO, 2013; SPIANDORELLO, 2014).

$A$ atenção dispensada aos métodos quantitativos se deve à confiabilidade fornecida quanto à apresentação dos resultados e as inferências realizadas. Para Spiandorello (2014), essa confiabilidade está sujeita a eficiência dos modelos quantitativos em que os experimentos sejam representativos do comportamento da população, além disso, o método adotado e sua operacionalidade devem ser explicitados, de modo que seja possível replicá-los. As inferências não devem ser guiadas pela necessidade do autor, mas sim, pelo resultado advindo do teste das hipóteses.

No entanto, pesquisas não relacionadas aos procedimentos invasivos em seres humanos e animais e aquelas que não tratam de conhecimento tradicional associado não se submetem, obrigatoriamente, a uma estrutura ou norma formal que possam incorrer sobre a utilização do método quantitativo proposto e a ética em sua aplicação. Como exemplo, têm-se as pesquisas relacionadas às Ciências Humanas, Sociais e Sociais Aplicadas, que embora possam ser utilizadas como referência para outras pesquisas, como plataforma para a criação e execução de políticas públicas e para a tomada de decisão, não são, em sua maioria, submetidas a comitês de éticas. Nessas pesquisas, a confiabilidade do método quantitativo pode ser utilizada para evidenciar um resultado premeditado pelos autores ou incorretamente alocado.

Dados apresentados por Chiarini e Vieira (2012) revelam que, em 2008, aproximadamente $36 \%$ dos grupos de pesquisa e $37 \%$ dos pesquisadores eram das áreas citadas e produziram $19 \%$ da produção bibliográfica e $8 \%$ da produ- 
ção tecnológica do total publicado a nível nacional. Os autores indicam, ainda, a concentração de egressos nos cursos relacionados a estas áreas.

Ainda que ocorra a existência da normatização formal e da estrutura administrativa que permite avaliar os preceitos éticos presentes em projetos científicos específicos nas IES, outros projetos não recebem a mesma atenção. No entanto, embora possam não acometer a integridade física de seres humanos e animais e a autoria dos conhecimentos tradicionais, essas pesquisas podem prejudicar a sociedade à medida que seus resultados possam motivar decisões generalizantes e políticas públicas. Neste sentido, este trabalho objetiva identificar quais as possíveis consequências da má conduta no planejamento, na execução e na análise de métodos quantitativos sobre a responsabilidade, assumida pelas IES, perante a sociedade.

Entende-se que os erros apresentados nas inferências de pesquisas, propositais ou não, podem acarretar em dispêndios financeiros significativos além de mudanças no modo de vida da população, ocasionando a dificuldade de manutenção da Responsabilidade Social pelas IES (FERREIRA; SAMPAIO, 2013; LIMA et al., 2012; MIRANDA, 2006; SPIANDORELLO, 2014).

O teste da hipótese proposta será realizado via pesquisa literária norteada pela identificação de casos de fraudes científicas cujos trabalhos foram, inicialmente, tidos como importantes e, por isso, replicados e referenciados por outros trabalhos e a mensuração das consequências que estes trouxeram para o meio acadêmico e para a sociedade. Faz-se também necessária a pesquisa relativa às possíveis falhas na utilização de métodos quantitativos e suas consequências para inferências. Ter-se-ia, assim, os efeitos ocasionados por fraudes já evidenciadas no meio científico, como um todo, e as potenciais fraudes e falhas características de pesquisas baseadas em métodos quantitativos e, a partir disso, pode-se inferir sobre a influência dos métodos quantitativos sobre o cumprimento da Responsabilidade Social pelas IES.

\section{Referencial Teórico e Metodológico}

A Responsabilidade Social das IES é apresentada pela Lei Federal $\mathrm{N}^{\circ}$ 10.861 de 14 de abril de 2004 e a Portaria N² 2.501 de 9 de julho de 2004, que a estabelece como uma das dez diretrizes de avaliação das IES (Brasil, 2004a, 2004b). A noção de Responsabilidade Social é definida por Ashley (2005) como toda ação que contribua para a melhoria da qualidade de vida da sociedade de forma contínua, além de atender a ética da comunidade que se insere.

A ética é aqui entendida como a definição dada por Aristóteles, em que o cidadão ético é virtuoso. Como consequência, tem-se que a sobreposição da razão sobre os instintos - em que as virtudes morais são estabelecidas pela aprendizagem informal no ambiente familiar e social - é subsidiada por virtudes intelectuais - caracterizadas como ações próprias da razão e que são repassadas durante o ensino formal - para aperfeiçoar as escolhas e decisões morais (CALOVI e MARMENTINI, 2010; SAGANTILI e STEFANI, 2012). 
A Responsabilidade Social das IES estaria, portanto, vinculada à ética em dois sentidos. O primeiro se refere à presença de investigadores que possuam virtudes morais e intelectuais bem desenvolvidas, condicionando visão de mundo que enalteça a razão, em detrimento da emoção, durante a construção de suas pesquisas. Assim, propiciaria o uso eficiente dos recursos empregados no desenvolvimento do conhecimento científico em resposta aos anseios sociais. Por outro lado, também é de responsabilidades das IES e de seus gestores, professores e pesquisadores, a formação de mão-de-obra eticamente capacitada para atuar no ambiente científico, para utilizar os dados e inferências apresentadas por publicações científicas como subsídio à tomada de decisão em empresas e no Estado. Além de formar cidadãos capacitados a interagir eticamente durante o processo de desenvolvimento socioeconômico (ASHLEY, 2005; CORREIA; ALVARENGA; GARCIA, 2011; LIMA et al., 2012).

Desta forma, o objetivo das IES ultrapassa os limites da formação e atualização de profissionais para atendimento ao mercado. Como afirmam Chiarini e Vieira (2012), essas instituições são as principais executoras de pesquisas científicas no Brasil, isto posto, seu objetivo também conforma a formação e atualização de cientistas, desenvolvimento de pesquisas científicas, além da interação direta com a sociedade, por meio de seus projetos de extensão.

Assim, além dos aspectos profissionais, as IES precisam supervisionar a ética na prática científica. Neste sentido, ainda que a ética norteie o planejamento, execução e divulgação dos projetos, as consequências do comportamento antiético podem ser visualizados, principalmente durante a fase de planejamento da pesquisa, pois é nesse momento em que são estabelecidos os princípios que nortearão a escolha de instrumentos e métodos a serem utilizados, além da organização, da análise de dados e a reflexão dos resultados que produzirão as inferências e recomendações que repercutirão sobre a comunidade acadêmica e a sociedade.

A motivação do cientista se basearia na moral do indivíduo (Sganzerla e Oliveira, 2012). Ao estabelecer a delimitação entre teorias científicas e não-científicas, Popper (2013) aciona a característica da "falseabilidade" como necessária para que uma teoria seja verdadeiramente científica. Isso significa que a própria construção teórica, que fundamenta os conjuntos de conceitos e previsões de uma teoria, deve possuir mecanismos de prova que permitam verificar sua veracidade. As teorias que não apresentam a característica da refutabilidade seriam consideradas não-científicas, pois, suas inferências seriam aplicadas em todas as observações empíricas sem que se possa identificar situações em que o pesquisador incorre no erro.

A questão moral define a real motivação das pesquisas, o que, de fato, se quer apresentar ao fim das etapas, o resultado dos testes das hipóteses ou uma verdade pré-concebida. Enquanto os testes das hipóteses forem o foco, a identificação da verdade ocorrerá a partir dos elementos e instrumentos disponíveis no momento, lançando mão de um Racionalismo Crítico, em que 
o saber apresenta condição permanentemente falível, conjectural e provisório, e que as teorias propostas devem ser postas à prova, por meio de sua falseabilidade. $\mathrm{O}$ trabalho científico deve, portanto, ser motivado pela busca da verdade, entendida como o resultado dos testes das hipóteses que os instrumentos e métodos atuais permitem realizar (GALVÁN, 2016; POPPER, 1994; SGANZERLA; OLIVEIRA, 2012).

Por outro lado, os trabalhos não-científicos procuram confirmar as teorias já estabelecidas, baseando-se no verificacionismo, em que se tenta provar, por meio de pesquisas empíricas, repetitivas e pontuais, que determinada teoria representa a verdade absoluta para explicar determinado fenômeno. Pesquisas com essa característica tendem a realizar suas etapas baseando-se na teoria proposta, de tal modo que todas as observações estão sempre carregadas de teoria. Identifica-se certo dogmatismo que enviesa todas as etapas para a confirmação da veracidade da teoria (POPPER, 2013; SANTOS, 2012; SGANZERLA; OLIVEIRA, 2012).

Os dogmas surgiriam da incompreensão das teorias como formas de "aproximação da verdade" possibilitadas e limitadas pelos instrumentos e técnicas científicas conhecidas. Essa limitação permite que a teoria seja refutada por experimentos e fatos reais, e até substituídas por teorias que lancem mão de novas técnicas e instrumentos. Pesquisas dogmáticas teriam como consequência atrasos no desenvolvimento científico motivados pela necessidade de se aceitar, pela fé, a verdade absoluta como superior a qualquer outra teoria (POPPER, 2009, 2013).

Desse modo, os agentes éticos deveriam realizar críticas a toda forma de conhecimento e administrar seus recursos, constantemente, em direção à busca da verdade. Não obstante, rejeitar a verdade absoluta não significa crença na verdade relativa. A verdade é objetiva, o relativismo se dá quanto à certeza que se tem sobre a observação individual e depende da conjuntura atual que limita a abrangência dos testes de hipóteses. Por esse motivo, a teoria aceita atualmente pode, no futuro, ser desacreditada devido ao desenvolvimento de novos instrumentos ou métodos que permitam teses, e por isso inferenciais, mais abrangentes. O comportamento ético, portanto, estaria no combate ao dogmatismo e ao relativismo (POPPER, 2013).

O objetivo da pesquisa ética, em seu início, deve ser o de encontrar a resposta mais próxima da realidade que os instrumentos e técnicas existentes the permitam, encontrando, assim, a verdade "provisória" que possibilita o avanço da ciência e abre caminho a novas pesquisas. Situação posterior a esta se dá pela responsabilidade do pesquisador em utilizar, corretamente, os recursos disponíveis para responder a um problema previamente proposto. Os investigadores precisam garantir total controle sobre a temática proposta, de modo a evitar assumir posições pessoais ou direcionar suas discussões para caminhos distintos àqueles que se situam na fronteira do conhecimento. A participação nas discussões mais avançadas permite o trabalho com conjunto metodológico também mais avançado. 
Conforme Russo (2014), a discussão sobre ética em pesquisas só se iniciou nos últimos anos devido, principalmente, à publicação do Código de Boas Práticas Científicas da Fundação de Amparo à Pesquisa do Estado de São Paulo (FAPESP) e do Relatório da Comissão de Integridade de Pesquisa do Conselho Nacional de Desenvolvimento Científico e Tecnológico (CNPQ).

O Código da FAPESP estabelece diretrizes que devem resultar na aplicação de valores fundamentais às diferentes etapas da atividade científica. A FAPESP atribui importância significativa aos "valores fundamentais" e cobra essa responsabilidade dos autores. Sobre as metodologias adotadas, o código afirma:

Ao conceber e realizar um projeto de pesquisa, o pesquisador deve lançar mão dos procedimentos que julgue serem cientificamente os mais apropriados e deve realizá-los da maneira que julgue ser cientificamente a mais apropriada para a obtenção dos fins científicos visados (FAPESP, 2014, art. 3.1.5).

Em outras palavras, caberá aos pesquisadores da comunidade acadêmica a virtude de realizar a revisão de literatura e aprendizado sobre a teorias e técnicas "mais apropriadas", ou mais avançadas. A Fundação reafirma a responsabilidade dos pesquisadores quanto ao uso dos seus recursos, quando afirma "o pesquisador deve estar convencido de que dispõe da capacidade científica para bem realizá-lo"(Fapesp, 2014 art. 3.1.2). Espera-se que os envolvidos tenham discernimento suficiente para que a pesquisa gere resultados científica e/ou socialmente relevantes, fazendo jus ao recurso empregado.

O Relatório publicado pelo CNPQ vai além e enfoca as consequências do comportamento oportunista durante a execução das pesquisas. Afirma que embora a ciência possua mecanismos de autocorreção, estes não são suficientes para impedir os "efeitos danosos advindos da fraude, seja por atrasar o avanço do conhecimento ou mesmo por consequências econômicas e sociais resultantes do falso conhecimento". Essas consequências se originam de falsificações (propositais ou não) no levantamento, manipulação, apresentação e inferências feitas a partir de dados e informações, além da prática do plágio responsáveis por custos financeiros e humanos envolvidos na correção dos desvios. A motivação individual estaria na possibilidade do contraventor em internalizar os benefícios da fraude, traduzidos em vantagens em sua carreira e na obtenção de auxílios financeiros. Em contrapartida, os custos financeiros e humanos envolvidos na correção dos desvios, são externalizados (CNPQ, 2011).

O relatório foi criado exatamente para instituir mecanismos, pedagógicos e coercitivos, que permitam "identificar e desestimular as práticas fraudulentas na pesquisa, e estimular a integridade na produção e publicação dos resultados de pesquisa". O documento finda com a disposição de 21 diretrizes referentes à correta citação de textos, conceitos e inferências já publicadas, definição sobre autoria dos artigos e responsabilidade sobre a veracidade do que foi escrito (CNPQ, 2011). 
Entendida como a contribuição dada, de forma ética, à sociedade (Ashley, 2005), a Responsabilidade Social é, portanto, uma das diretrizes a ser atendida pelas IES, em todo o país (Brasil, 2004a; Brasil, 2004b). Assim, do ponto de vista ético, o cumprimento dessa diretriz pode ser prejudicado por ações antiéticas realizadas por pesquisadores, professores e estudantes, à medida em que a moral, possivelmente enviesada, possa levar a motivações conclusivas, de tal modo que a pesquisa é planejada para que as sucessivas etapas confirmem a hipótese desejada. Ter-se-iam inferências frágeis e possivelmente equivocadas, mas que se tornam fortes e corretas por possuírem a chancela das Instituições de Ensino (Fapesp, 2014; Popper, 2013; Spiandorello, 2014; Volpato, 2001). Sendo assim, a atitude antiética na condução de pesquisas científicas pode sim ocasionar dificuldades para que as IES correspondam à Responsabilidade Social esperada pela sociedade e registrada por meio de Lei.

A estatística também pode produzir resultados errôneos. Muitas vezes considerados essenciais para a garantia de confiabilidade da pesquisa, os métodos quantitativos, aos quais a estatística faz parte, permitem que o teste de hipótese se realize a partir da procura por evidências probabilísticas que induzam a aceitação ou rejeição da hipótese (Spiandorello, 2014). Incorre-se a possibilidade de erros involuntários, mas ainda de responsabilidade dos pesquisadores, como descrito no Código de Boas Práticas da FAPESP (2014) e de erros intencionais, motivados por atitudes antiéticas e centrados na necessidade, moralmente questionável, de se comprovar, a qualquer custo, uma teoria ou ideologia defendida pelos pesquisadores. Esses erros podem ocorrer na escolha do método, no planejamento para execução, durante a execução e também durante a análise de seus resultados.

Do ponto de vista ético, nos desvios morais que enviesam a motivação e desvirtuam a cientificidade do método quantitativo, corre-se o mesmo risco de outros métodos (Spiandorello, 2014). A escolha do método ou ferramenta estatística a ser seguida pode ser feita por sua facilidade em se comprovar o resultado esperado e não por ser esta a mais avançada para se estudar a hipótese levantada. O planejamento pode, entre outras coisas, agendar a coleta de dados para períodos ou regiões em que a variável analisada apresente o resultado esperado, ao invés de procurar maior variabilidade. A execução pode ser realizada de modo a moldar os dados para que os testes estatísticos de validação de hipóteses sejam atendidos, ainda que os dados e a forma de coleta indiquem o contrário.

Ainda que se observe a possibilidade de má conduta durante a utilização de método quantitativo, não se obtêm mecanismos sofisticados de controle e correção como aqueles analisados para práticas científicas envolvendo seres humanos, animais e conhecimento tradicional associado (Spiandorello, 2014).

A Resolução CNS Nº 466 de 10 de outubro de 1996 afirma: 
As pesquisas, em qualquer área do conhecimento envolvendo seres humanos, deverão [...] utilizar os métodos adequados para responder às questões estudadas, especificando-os seja a pesquisa qualitativa, quantitativa ou quali-quantitativa (CNS, 1996 III.2 e,).

A legislação prevê, portanto, a necessidade de controle sobre o método de pesquisa a ser aplicado em trabalhos que envolvam seres humanos. Ainda assim, conforme indica Spiandorello (2014), embora necessários, são poucos os relatos de verificação do método quantitativo empregado, principalmente quanto a seus aspectos teóricos.

Conforme Zito-Guerreiro (2015), atualmente existe um Grupo de TrabaIho no CONEP, composto por 18 associações nacionais de pesquisa e pós-graduação relacionadas a diferentes áreas das ciências sociais e humanas, criado com o objetivo de elaborar uma resolução de pesquisa em ciências sociais e humanas para compor o banco de resolução do conselho.

Ainda que o sistema composto por CEP e CONEP apresente falhas evidenciadas em atrasos e recusas sem que os projetos apresentem faltas éticas (Zito Guerreiro e Bosi, 2015), sua estrutura permite que faltas éticas sejam reduzidas, no que tange aos preceitos indicados no Relatório produzido pelo CNPQ e pelo Código disponibilizado pela FAPESP (Cnpq, 2011; Fapesp, 2014; Spiandorello, 2014). Ressalta-se que, embora exista a iniciativa de produção de resolução que trate da ética das ciências humanas e sociais, não se encontram, atualmente, registros de regulamentação oficial relativa à necessidade de fiscalização, por meio de Comitês ou outra estrutura, de trabalhos que lancem mão de métodos quantitativos, mas não têm como objeto de estudo humanos, animais e o conhecimento tradicional. Esses projetos só serão fiscalizados pela comunidade científica após a publicação do resultado da pesquisa. O que se observa é a existência de princípios éticos gerais e regras metodológicas que, embora auxiliem os pesquisadores para que tenham boas práticas, não se apresentam na forma de Lei ou são fiscalizadas de alguma forma.

Infere-se, portanto, que a atitude antiética também afeta a utilização de métodos quantitativos de tal modo que estes possam afetar o cumprimento da Responsabilidade Social das IES. Neste sentido, este trabalho objetiva identificar quais as possíveis consequências da má conduta no planejamento, na execução e na análise de métodos quantitativos sobre a responsabilidade, assumida pelas IES, perante a sociedade. Para tanto, buscou-se contextualizar a influência do comportamento ético, em pesquisas científicas que se utilizem de métodos quantitativos, sobre a contribuição das IES para a sociedade, conforme apresentado nesta seção. As consequências da atitude antiética, para o cumprimento da Responsabilidade Social, pelas IES, serão abordadas via pesquisa literária relativa a casos clássicos de fraudes, não necessariamente relacionados ao uso de métodos quantitativos. Acredita-se que embora ocorram em métodos ou etapas distintas, as consequências da realização e da publicação de resultados de pesquisas fraudadas sejam semelhantes. 
Trata-se, portanto, de uma pesquisa exploratória executada por meio de pesquisa bibliográfica em que a pesquisa preliminar, baseada na conceituação da ética aristotélica e sua importância para o atendimento à Responsabilidade Social, por parte das IES, permitiu a formulação do problema proposto. Como fontes bibliográficas foram selecionados artigos científicos publicados e disponibilizados na plataforma de periódicos da CAPES, cujo assunto se refira à Ética na Ciência, Ética em Pesquisas Científicas, Responsabilidade Social das IES e a Ética no uso de Métodos Quantitativos. Desde então, prosseguiu-se com a pesquisa referente à legislação citada nos trabalhos encontrados na primeira etapa. A partir da leitura, fichamento e organização de todo material, identificaram-se três casos, de maior destaque, de fraudes em trabalhos científicos. Esses casos serão apresentados para que se tenha conhecimento de suas consequências sobre a comunidade científica e a sociedade. Além disso, também serão apresentados os principais erros cometidos durante a utilização de métodos quantitativos.

\section{Apresentação e Discussão dos Resultados}

Conforme explicitado nas seções anteriores, a aplicação de métodos quantitativos exerce significativa influência sobre a contribuição das IES junto à sociedade, segundo enunciado pela dimensão da Responsabilidade Social. Neste sentido, os trabalhos publicados por Zito Guerreiro (2015) e Zito Guerreiro e Bosi (2015) indicam a necessidade de fiscalização de pesquisas produzidas pelas ciências sociais e humanas que estejam relacionadas com a saúde. Também revelam a existência de um Grupo de Trabalho com o objetivo de desenvolver uma resolução, específica para esses casos, a ser publicada pelo CNS. Spiandorello (2014) vai além e cita a necessidade de fiscalização dos métodos quantitativos empregados em todas as pesquisas voltadas a saúde. Revela-se, assim, a emergência no estabelecimento de mecanismos de acompanhamento da aplicação de métodos quantitativos mesmo em pesquisas relacionadas a áreas de estudos já normatizadas. Defende-se, no entanto, a necessidade de maior abrangência da atuação dos comitês, que devem ir além de pesquisas relacionadas à saúde e ao conhecimento tradicional, atingindo todas as pesquisas financiadas e realizadas por IES e que lancem mão de ferramentas quantitativas.

Os métodos quantitativos têm o papel de possibilidade da descrição quantitativa de fenômenos sociais ou naturais. Utilizando-se de teorias quantitativas, principalmente a probabilidade e a correlação, é permitido aos pesquisadores controlar os acontecimentos em estudos por meio de abordagem simplificada, mas cientificamente suficiente para sua compreensão (Marconi e Lakatos, 2017; Prodanov e Freitas, 2013). Na ciência da saúde, por exemplo, a probabilidade permite que o teste de eficiência de medicamentos e tratamentos seja realizado em uma pequena amostra de voluntários, garantindo que seu resultado represente a resposta ao uso da medicação na população. 
A determinação do risco de contaminação por dada patologia também pode ser inferida a partir da construção de modelagem quantitativa, baseada no conhecimento de seu comportamento, em que se investigue a correlação entre a doença e as variáveis explicativas.

Nas ciências sociais, sociais aplicadas e humanas, a importância dos modelos quantitativos é ainda maior, à medida em que o objeto de estudo não pode ser diretamente conduzido, ou, quando isso é possível, não se tem acesso ao total do espaço amostral. Essa característica confere aos métodos estatísticos, econométricos, multivariados e outros, um papel fundamental para investigação científica nos campos citados (Marconi e Lakatos, 2013; Prodanov e Freitas, 2013). A literatura é rica em trabalhos que apresentam dados relativos que permitem a promoção de políticas que objetivem a redução de crimes, ao crescimento econômico, redução da pobreza, entre outros. Em comum, algumas possuem a adoção de ferramentas quantitativas que permitem o convencimento da sociedade sobre sua importância. Não obstante, é comum observar a apresentação de trabalhos complementares em uma síntese representada por uma probabilidade de que determinado evento ocorra ou de que uma dada variável influencie outra. Apresentam-se dois casos em que a relação entre resultado da pesquisa, sua aceitação pela sociedade e a decorrente utilização como base de políticas públicas se tornam evidentes.

Em que pese a existência de vários ferramentais e possibilidades de uso, ressalta-se a aplicação de métodos quantitativos em trabalhos utilizados como base para a tomada de decisão. Utilizando os multiplicadores de emprego, renda e produto, além dos efeitos de encadeamento produtivo entre os setores, Figueiredo e outros (2011) concluem que as cadeias do agronegócio são essenciais para a dinamicidade da economia do estado e Mato Grosso. Em paralelo, identificaram elos frágeis que limitam o desenvolvimento de determinadas cadeias produtivas. Utilizando metodologia semelhante, Brasileiro (2012) estima o Produto Interno Bruto Ajustado Ambientalmente para a Amazônia Brasileira, adotando as emissões de gases do efeito estufa como fator de ajuste ambiental. Como resultado, o PIB convencional estaria superestimado em 15\% em decorrência da não consideração dos impactos das atividades econômicas sobre a camada de ozônio. Tratam-se de pesquisas desenvolvidas com recursos públicos; o primeiro resultado de um termo de cooperação entre o Governo do Estado de Mato Grosso e a Universidade Federal de Mato Grosso e o segundo o resultado final de uma pesquisa de mestrado.

Nos dois casos, as conclusões alcançadas permitem que políticas públicas sejam criadas para corrigir distorções que afetam direta ou indiretamente a população. Essas ferramentas são utilizadas para fundamentar a política de crescimento econômico a partir do incentivo fiscal e financeiro de alguns setores tidos como fundamentais. Neste sentido, o fortalecimento dos elos frágeis, identificados por Figueiredo et al. (2011), em algumas cadeias produtivas estratégicas para o Estado, visando impulsionar a geração de emprego e renda e 
a adoção de medidas para mitigação dos impactos sobre a camada de ozônio, como evidenciado no segundo trabalho, são exemplos da interação entre IES e a sociedade em que desvios éticos podem produzir impactos negativos sobre o desenvolvimento socioeconômico. Se os elos frágeis, identificados no primeiro trabalho, não se apresentarem como setores-chave, mas os resultados do trabalho afirmarem o contrário, os recursos humanos e financeiros que abarcam as políticas de promoção ao crescimento adotadas poderão direcionar recursos para setores de baixo impacto, em detrimento de setores que trariam benefícios superiores à sociedade.

Entende-se que os dois trabalhos seguiram os preceitos éticos e metodológicos que o rigor da ciência e as características do método escolhido exigem. No entanto, se não o fossem, a Responsabilidade Social das IES envolvidas estaria comprometida em duas frentes. A primeira se refere ao aspecto financeiro, internamente, recursos teriam sido despendidos para uma pesquisa cujo resultado não ocasionou benefícios sociais, ao contrário, e em decorrência disso, ações estatais foram realizadas equivocadamente ao direcionar recursos a setores não relevantes, como para a matriz aplicada ao Mato Grosso, ou ao controlar e penalizar atividades com baixa emissão de gases do efeito estufa, no caso da matriz aplicada à Amazônia. Revela-se custo de oportunidade negativo. Em segundo lugar, ter-se-ia quantidade inferior de emprego e renda, ocasionados pelo incentivo estatal, ao crescimento econômico, de forma equivocada.

Como os trabalhos não apresentam tais falhas éticas, não é possível expressar a dimensão dos possíveis impactos da ausência de ética de seus pesquisadores. Destarte, apresentam-se três outros casos em que tal dimensão é verificada, ainda que do ponto de vista científico. A teoria da evolução humana darwinista teria sido comprovada em 1913 quando da descoberta do "homem de Piltdown", um crânio fóssil, datado com mil anos e considerado o "elo perdido" na evolução da humanidade (Cnpq, 2011). Após 40 anos, em que os estudos sobre o tema foram desenvolvidos a partir dessa descoberta, a fraude foi revelada. $\mathrm{O}$ advento de novas tecnologias de datação arqueológica viriam a corrigir a idade do fóssil para seiscentos anos. Além disso, foram identificadas marcas de cortes propositais, rastros de produtos químicos e ossos de animais na composição do crânio (OAKLEY e GROVES, 1970).

As publicações do coreano Woo-Suk Hwang, na Science, entre 2004 e 2005, divulgaram à comunidade científica mundial a clonagem de células-tronco sadias (2004) e doentes (2005), tratando-se do primeiro caso de clonagem de células-tronco de adultos na história da ciência e que rendeu a ele o status de "importante pesquisador", além da liberação de vultuosos recursos para pesquisas futuras (Cnpq, 2011). No entanto, ainda em 2005, a auditoria identificou que nenhuma das células-tronco criadas possuíam materiais genéticos iguais aos seus doadores. Novamente, têm-se a manipulações de dados reais, obtidos durante pesquisa científica, para chegar a inferências tendenciosas (WILMUT et al., 2005). 
Nos dois casos, ao não alcançar o resultado esperado, os investigadores decidem por manipular os dados da pesquisa para que sejam permitidas as inferências almejadas. $O$ "prêmio" pela fraude advém da publicação de seus resultados, que ao mesmo tempo aciona o mecanismo de autorregulação, responsável por identificar e expor a manipulação, descredenciando a publicação e seus autores. Esse hiato, em que a falsa inferência é tida como verdadeira, permite a mobilização de recursos para estudos baseados em seus resultados e inutiliza determinadas inferências contrárias, desarticulando o caminho de construção do conhecimento científico, como observado nas pesquisas de Hwang e do "homem de Piltdown".

As consequências da fraude podem ser ainda mais desastrosas, interferindo nas decisões relativas ao desenvolvimento da sociedade. A manipulação de dados e informações pelo engenheiro agrônomo soviético Trofim Lysenko ilustra essa afirmativa. Lysenko era presidente da Academia Soviética de Ciências durante os regimes de Josef Stalin e Nikita Khruchtchev e objetivava levar o estudo sobre genética ao descrédito. Para isso, desenvolveu sua própria teoria biológica manipulando os dados de pesquisas em campo para provar a existência de supostas falhas na genética mendeliana. Como resultado, o governo soviético interrompeu o ensino sobre genética, durante 16 anos, e decidiu pelo não cultivo de milho híbrido nas quintas coletivas (Almazana, 2010). Paralelamente, o Estado pretere e persegue geneticista retrocedendo o conhecimento científico da comunidade local (SOYFER, 2001).

A pseudociência executada por Lysenko se impôs como dominante e causou fortes impactos negativos sobre a comunidade científica russa e sua população (Almazana, 2010). As pesquisas executadas pelo agrônomo objetivaram provar que a genética mendeliana se tratava de uma "perversão burguesa" e estratagema para incentivo à discriminação racial, sendo assim desprovida de caráter científico (Soyfer, 2001). Constata-se, assim, que o trabalho de Lysenko seria pautado no dogmatismo, pois direciona o planejamento e execução de suas pesquisas para a comprovação de sua verdade absoluta.

Lysenko utilizou a força do Estado para propagar sua teoria e repelir pensamentos distintos, como pensamento hegemônico em seu país, suas conclusões serviam de base para as decisões estatais relativas ao direcionamento da produção rural no país. Sua repulsa pelo cultivo do milho híbrido como forma de melhorar a produtividade é apontada como uma das principais causas do insucesso do modelo rural soviético, levando ao atraso do desenvolvimento daquela nação (ALMAZANA, 2010).

Os casos reais apresentados como exemplo enunciam os danos financeiros e científicos ocasionados por práticas antiéticas no ambiente científico. Se por um lado recursos financeiros foram despendidos com o financiamento de pesquisas fraudulentas, e com a replicação de seus resultados, por outro, os avanços científicos teóricos e empíricos são comprometidos. Esses casos trouxeram impactos internacionais pois esforços, tempo e recursos foram despen- 
didos em novas pesquisas que tentaram replicar os estudos em evidência e utilizá-los como base para possíveis avanços. No Brasil, essa situação se agrava à medida que a maior parte das pesquisas são gestadas e executadas por IES, significando que a maior parte do financiamento é garantido pelo Estado. Nesta situação, uma única pesquisa fraudulenta, que ganhe evidência, pode atravancar o desenvolvimento científico nacional, à medida que direciona esforços e recursos na direção revelada pelo estudo fraudado afetando a disponibilidade de recursos para futuras pesquisas. Além disso, o caso de Lysenko deixa claro como uma pesquisa tida como científica pode levar consequências negativas ao conjunto da sociedade. Sua fraude não prejudicou somente o desenvolvimento da ciência em seu país, como negou o acesso, à população, da maior quantidade de alimentos e menores os preços decorrentes.

Neste contexto, pode-se indicar a estatística como uma das ferramentas úteis aos fraudadores. Utilizados em todas áreas de ciência como forma de estruturar a pesquisa e de aplicar a metodologia, os métodos estatísticos proporcionam resultados e conclusões do estudo quantitativo. Como resultado, tem-se a possibilidade de obtenção de resultados diferentes, conforme a análise estatística adotada.

Desse modo, o pleno conhecimento estatístico não é suficiente para pesquisa e publicação de trabalhos em várias áreas do conhecimento, ao contrário, o pesquisador e sua equipe devem controlar os aspectos teóricos e práticos relativos à área de conhecimento trabalhada e também os fundamentos estatísticos, de modo a selecionar o método quantitativo que melhor se aplique a seu contexto (SPIANDORELLO, 2014).

A definição da amostra de modo a representar corretamente a população não é uma atividade trivial. O tamanho, a característica e a forma de abordagem dependem do problema a que se quer responder e do método que permitirá o tratamento dos dados. Pesquisa em que questionários são aplicados com intuito de identificar as motivações de determinada conduta da população em uma cidade deve ter quantidade mínima que represente o comportamento total da população, e sua aplicação deve ser aleatória, mas abranger a maior parte possível dos bairros, de modo a captar a variabilidade de comportamentos. Mesmo a elaboração dos questionários demanda atenção, a definição das perguntas que realmente permitem a resolução do problema da pesquisa e o formato definido para as respostas também podem inviabilizar o trabalho.

O tratamento dos dados depende do formato da amostra, variáveis quantitativas são trabalhadas com determinados métodos específicos distintos daqueles destinados às variáveis qualitativas. Essas variáveis podem ainda ser divididas em discretas e contínuas, no caso das quantitativas, e nominais e ordinais, no caso das qualitativas. Embora existam métodos que permitam a utilização das variáveis em conjunto, é necessário interpretar as saídas conforme as características e as informações inseridas. E ainda que o pesquisador tenha pleno controle sobre essas questões, ele ainda terá que decidir quais testes irá utilizar considerando suas limitações. 
Embora os resultados sejam objetivos, a sua construção é completamente subjetiva. Desde a definição da amostra representativa, a escolha dos métodos e testes de hipóteses até a análise dos resultados à luz da teoria, cabe ao pesquisador todas as decisões e com isso o caminho a ser seguido pela investigação. Considerando que a pesquisa ética é aquela que contribui ao conhecimento científico e ao desenvolvimento da sociedade, a ética do pesquisador ao utilizar os métodos quantitativos é essencial. O monitoramento da prática ética em pesquisas científicas deveriam abarcar o tratamento dos dados quantitativos, não só quanto ao levantamento dos dados, mas também quanto aos métodos escolhidos para testar as hipóteses propostas. A ausência desse monitoramento nas IES pode comprometer o cumprimento de sua Responsabilidade Social.

\section{Considerações Finais}

A ética, no ambiente de Ensino Superior, não pode se restringir às práticas formais de trabalho. Além de exercitar o rigor ético, no cumprimento das regras estabelecidas e no respeito aos companheiros de trabalhos e aos alunos, professores do magistério superior necessitam praticar e ensinar a ética científica. Os procedimentos que compõem as etapas do processo do "fazer científico" devem ser completamente controlados por seus participantes, de modo que as inferências sejam pautadas nos melhores instrumentos e técnicas disponíveis.

A hegemonia dessas práticas levaria ao cumprimento da Responsabilidade Social quanto à formação de cidadãos éticos, capazes de interagir com a sociedade por meio de suas atividades, interpretando o caminho indicado pela ciência e adaptando suas atividades em busca do desenvolvimento. Por outro lado, as pesquisas internamente executadas, pelas IES, corresponderiam à busca pela verdade, respondendo aos grandes problemas sociais e ao avanço do conhecimento.

Imersos na maior parte das áreas da ciência, os métodos quantitativos são essenciais para o manuseio de dados e informações, fato que possibilita seu uso para manipulação de informações. Desse modo, acredita-se que a ética no uso das ferramentas ofertadas por esses métodos seja essencial para que as IES cumpram sua Responsabilidade Social. A ausência da ética poderá trazer consequências financeiras e sociais conforme demostrado nos exemplos ilustrativos e reais apresentados na discussão, principalmente, no caso de Lysenko, que se espera não ser reprisado por trabalhos utilizados como referência na promoção de políticas públicas. 
RESPONSABILIDADE SOCIAL E A ÉTICA NO USO DE MÉTODOS QUANTITATIVOS NO ENSINO SUPERIOR

\section{Referências}

ALMAZANA, V. G. La Seudociencia en Trofim Denissovitch Lysenko. CULCyT: Cultura Científica y Tecnológica, v. 7, n. 38/39, p. 30-34, 2010.

ASHLEY, P. A. Responsabilidade social empresarial: um modelo genérico para análise e orientação estratégica. In: ASHLEY, P. A. (Ed.). . Ética e responsabilidade social nos negócios. 2a ed. São Paulo: Saraiva, 2005.

BRASIL, L. No 10. 86. DE 14 DE ABRIL DE 2004. Institui o Sistema Nacional de Avaliação da Educação Superior - SINAES, 2004a.

BRASIL, P. No 2. 50. DE 9 DE JULHO DE 2004. Regulamenta os procedimentos de avaliação do Sistema Nacional de Avaliação da Educação Superior (SINAES), 2004b.

BRASILEIRO, A. C. B. Produto interno bruto ajustado ambientalmente para Amazônia legal brasileira: uma análise de matriz de insumo-produto e matriz de contabilidade social. [s.l.] Universidade de São Paulo, 2012

CALOVI, G. E.; MARMENTINI, G. L. A Ética Aristotélica. Mirabilia Journal, v. 11, n. 2, p. 59-79, 2010.

CHIARINI, T.; VIEIRA, K. P. Universidades como produtoras de conhecimento para o desenvolvimento econômico: sistema superior de ensino e as políticas de CT\&I. Revista Brasileira de Economia, v. 66, n. 1, p. 117132,2012

CNPQ, C. N. DE D. C. E T. Relatório da Comissão de Integridade de Pesquisa do CNPqBrasília, 2011.

CNS, R. No 196 DE 10 DE OUTUBRO DE 1996. Diretrizes e Normas Regulamentadoras de Pesquisas Envolvendo Seres Humanos, 1996.

CORREIA, A. E. G. C.; ALVARENGA, L.; GARCIA, J. C. R. Publicar é preciso, transformar cientistas em máquinas de produção não é preciso. Datagramazero - Revista de Ciência da Informação, v. 12, n. 3, p. 1-20, 2011.

FAPESP, F. DE A. À P. DO E. DE S. P. Código de Boas Práticas Científicas. 2014.

FERREIRA, S. N.; SAMPAIO, M. J. A. M. Pesquisa Científica e Acesso a Recursos Genéticos: Implementação da Legislação de Acesso a Repartição de Benefícios no Brasil. Brasília: SBPC, 2013.

FIGUEIREDO, M. G. DE et al. Matriz Insumo-Produto de Mato Grosso 2007: Construção e Análise dos Principais Indicadores Econômicos. Revista de Estudos Sociais, v. 13, n. 26, p. 49-73, 2011.

GALVÁN, M. Racionalismo crítico e interpretación. Ideas y Valores, v. Ixv, n. 160, p. 239-251, 2016.

LIMA, A. P. L. DE et al. Conceitos, Práticas e Desafios da Responsabilidade Social na Produção Científica.

Perspectivas em Gestão \& Conhecimento, v. 2, n. 2, p. 30-42, 2012.

MARCONI, M. DE A.; LAKATOS, E. M. Técnicas de Pesquisa. São Paulo: Atlas, 2013.

MARCONI, M. DE A.; LAKATOS, E. M. Fundamentos de Metodologia Científica. 8. ed. São Paulo: Atlas, 2017.

MIRANDA, L. C. D. DE. A Produção Científica E a Ética Em Pesquisa. Rev Col Bras Cir, v. 33, n. 6, p. 15-16, 2006.

OAKLEY, K. P.; GROVES, C. P. Piltdown man: the realization of fraudulence. Science, v. 169, n. 947, p. 789, 1970.

POPPER, K. R. En busca de un mundo mejor. 1o edição ed. Barcelona: Paiados Iberica, 1994.

POPPER, K. R. O mito do contexto: Em defesa da Ciência e da Racionalidade. Lisboa: 70, 2009.

POPPER, K. R. A lógica da pesquisa científica. 2a edição ed. São Paulo: Editora Cultrix, 2013.

PRODANOV, C. C.; FREITAS, E. C. DE. Metodologia do trabalho científico: métodos e técnicas da pesquisa e do trabalho acadêmico. Novo Hamburgo, RS: Universidade FEEVALE, 2013.

RUSSO, M. Ética e Integridade na Ciência: da responsabilidade do cientista à responsabilidade coletiva. Estudos Avançados, v. 28, n. 80, p. 189-198, 2014

SANGALI, I. J.; STEFANI, J. Noções introdutórias sobre a ética das virtudes aristotélica. Conjectura: filosofia e educaçãofórmula de lançamento, v. 17, n. 3, p. 49-68, 2012. 
SANTOS, J. F. DOS. O Realismo em Popper e Peirce: Um Contraponto. In: OLIVEIRA, P. E. DE (Ed.). . Ensaios sobre o pensamento de Karl Popper. Curitiba: Círculo de Estudos Bandeirantes, 2012. p. 113-133.

SGANZERLA, A.; OLIVEIRA, P. E. DE. Da Relação Entre Ética e Ciência: Uma Análise a Partir da Epistemologia de Karl Popper. Princípios Revista de Filosofia, v. V. 19, n. 31, p. 327-349, 2012.

SOYFER, V. N. The consequences of political dictatorship for Russian science. Nat Rev Genet, v. 2, n. 9, p. 723-729, set. 2001.

SPIANDORELLO, W. P. O papel do comitê de ética em pesquisa na avaliação de testes estatísticos. Rev. bioét. (Impr.)., v. 22, n. 3, p. 471-481, 2014.

VOLPATO, G. Ética na Ciência. Caunesp Notícias, v. VIII, n. 24, p. 3, 2001.

WILMUT, I. et al. Human Embryonic Stem Cells. Science, v. 310, n. December, p. 1903-1904, 2005.

ZITO GUERREIRO, I. C. O Desafio da Elaboração de Diretrizes Éticas Específicas para Ciências Sociais e Humanas no Brasil. Rev. Fac. Nac. Salud Pública Vol., v. 33, n. Supl 1, p. S93-S95, 2015.

ZITO GUERREIRO, I. C.; BOSI, M. L. M. Ética em Pesquisa na Dinâmica do Campo Científico: Desafios na Construção de Diretrizes para Ciências Humanas e Sociais. Ciências e Saúde Coletiva, v. 20, n. 9, p. 2615-2624, 2015. 